Bangladesh Journal of Anatomy January 2014, Vol. 12, No. 1 pp. 7-10

\title{
A Cross Sectional Study on Sex Difference in sagittal Length of Second Cervical Vertebrae
}

\author{
Masuma Akhtar Banu' ${ }^{1}$, Shamim Ara², Borhan Uddin Ahamed ${ }^{3}$, Sharmin Rahman ${ }^{4}$, Yesmin $^{2}$ \\ Nahar ${ }^{5}$, Rahanur Akhter ${ }^{6}$
}

\begin{abstract}
:
Context: Examination of bone is important for identification of sex of an individual. The present study was planned to collect data regarding sagittal length of human dry ossified second cervical vertebrae and to find out possible variations in male and female.

Materials \& Methods: A cross-sectional analytical type of study was conducted in the department of Anatomy, Dhaka Medical College, Dhaka, from January 2012 to December 2012. The study materials consist of 156 human dry ossified second cervical vertebrae of unknown sex. The study samples were distributed in male and female sex groups by discriminant function analysis technique.

Results: Among 156 vertebrae $55.77 \%$ was male and $44.23 \%$ was female. The mean ( $\pm S D$ ) sagittal length of second cervical vertebrae was greater in male than that of female $(P<0.001)$.

Conclusion: Sagittal length of second cervical vertebra was greater in male compared to female. The differences in length can be useful in sex differentiation.
\end{abstract}

Key words: Sagittal length, second cervical vertebra, sex, discriminant analysis technique.

\section{Introduction}

Axis is the second cervical vertebra and is characterized by the dens or odontoid process, body, weight bearing superior articular facets and a large spinous process ${ }^{1}$. The second cervical vertebra is unique in shape and allows rotation of head. The axis permits the "No" gesture type of rotation. The body of the second cervical vertebra is composite and consists of the partly fused centra of the atlas and axis and a rudimentary disc between them ${ }^{2}$. In severe injuries due to motor vehicle collisions, assaults and falls, the body of the second cervical vertebra is displaced anteriorly with respect to the

1. Assistant Professor, Department of Anatomy, Uttara Adhunik Medical College

2. Professor and Head, Department of Anatomy, Dhaka Medical College

3. Associate Professor, Department of Forensic Medicine, Monno Medical College

4. Assistant Professor, Department of Anatomy, Ad-din Women's Medical College

5. Assistant Professor, Department of Anatomy, City Medical College

6. Lecturer, Department of Anatomy, Shaheed Suhrawardy Medical College

Correspondence : Dr. Masuma Akhtar Banu body of the third cervical vertebra. At second cervical vertebra, most individuals (91\%) present bifid spinous process ${ }^{3}$. Lower surface of spinous process of second cervical vertebra is grooved and ends in a wide bifurcation. The tip of spinous process resembles an inverted $U^{1}$. The sagittal length of second cervical vertebra is the difference between the most anterior point of the body and the most posterior point of the most projecting part of bifid spinous process ${ }^{4-6}$.

It has widely been recognized that skeletal characteristics vary among populations. So each population should have specific standards to optimize the accuracy of identification. Though use of the entire skeleton is optimal for estimating sex of an individual, complete skeletal remains are often not available. Some skeletal elements such asskull, foramen magnum, vertebrae, pelvis, sacrum, humerus provide better estimation of sex than other skeletal elements. Determination of sex is estimated by second cervical vertebrae in forensic or archaeological situation 7 . The sagittal length is by far the best single variable for estimation of $\operatorname{sex}^{4-6}$. 
So far it is known the morphometric measurement of second cervical vertebrae have not yet been studied in Bangladesh. This study was undertaken to measure the sagittal length of second cervical vertebrae and to evaluate the difference in length of the same between male and female. The study is expected to be helpful for the forensic experts and anthropologists for determination of sex from the second cervical vertebrae collected from Bangladesh. It may also be beneficial for spine surgeons and radiologists for diagnosis of traumatic, congenital disorder and treatment of cervical instability, spinal trauma and extensive laminectomies.

\section{Materials and Methods}

A total of 156 human dry ossified second cervical vertebrae of unknown sex were collected purposively from the Department of Anatomy of Dhaka Medical College and other government and non-government Medical Colleges in Dhaka. Then the sexes of collected vertebrae were determined by a multivariate linear discriminant function analysis technique. This multivariate linear discriminant analysis technique was applied to the collected data is as follows-

$z=b_{0}+x_{1} b_{1}+x_{2} b_{2}+\ldots \ldots \ldots+x_{n} b_{n}$

Here $b_{0}$ is constant, $b_{1}$ to $b_{n}$ are the coefficients and $x_{1}$ to $x_{n}$ are the variables which is mentioned below-

$\mathrm{X}_{1}=$ height of anterior surface of dens (independent variable).

$\mathrm{X}_{2}=$ height of anterior surface of the body of second cervical vertebra (independent variable).

In this study the value of $Z$ for each specimen was calculated by substituting the values of the variables in the linear function. A sectioning point (SP) was created by using the mean discriminant scores. To assign the case to either male or female sex, the product $Z$ was compared to the sectioning point derived by the discriminant function. A value higher than the sectioning point was considered to be male and a value below it was considered to be female. By discriminant analysis technique the sex was determined and the grouping was done.
Afterwards for the measurement of sagittal length of second cervical vertebrae, the most anterior point of the body and the most posterior point of the most projecting part of bifid spinous process of second cervical vertebrae were determined. A red dot was given on the most anterior point of the body of second cervical vertebra. Another blue dot was given on the most posterior point of spinous process. Then sagittal length of second cervical vertebra was measured as the distance between the two determined points with the help of digital slide calipers and the reading was recorded (Fig.-1).

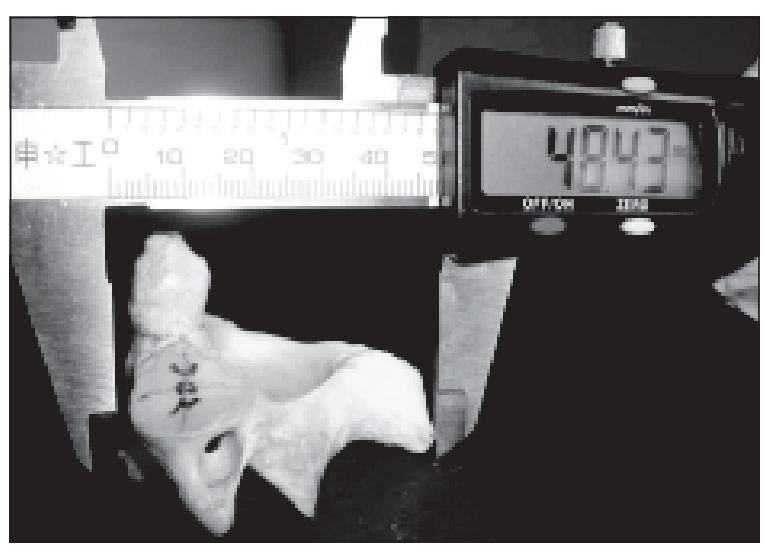

Fig.-1: Photograph showing the measurement of sagittal length of second cervical vertebra by using digital slide calipers. The dot in the body indicates most anterior point of it and the dot in spinous process indicates most posterior point of it.

After collection of data, the findings of this study was analyzed by SPSS version 17 and revealed important information regarding morphometric variation. Comparison of the values of different variables between male and female was done by unpaired Student's't' test.

\section{Ethical clearance}

This study was approved by Ethical Review committee of Dhaka Medical College.

\section{Results}

The dry ossified second cervical vertebrae were grouped into male and female by discriminant function analysis technique (Table-I). 
Table-I

Distribution of study subjects into different sex according to discriminant function analysis technique

\begin{tabular}{lcc}
\hline Sex & $\begin{array}{c}\text { Number of second cervical } \\
\text { vertebra }(\mathrm{n})\end{array}$ & Total (\%) \\
\hline Male & 87 & 55.77 \\
Female & 69 & 44.23 \\
\hline
\end{tabular}

The range of sagittal length was $38.28-53.49 \mathrm{~mm}$ in male and 35.20-53.02 mm in female. The mean ( \pm $\mathrm{SD})$ sagittal length of the second cervical vertebrae in male and female were $46.46 \pm 2.62 \mathrm{~mm}$ and $44.73 \pm$ $3.27 \mathrm{~mm}$ respectively. The mean sagittal length of the second cervical vertebrae was significantly higher in male than that of female $(P<0.001)$ (Fig.-2).



\section{Discussion}

In the present study the mean sagittal length of second cervical vertebrae was significantly $(P<0.001)$ greater in male than that of female $(p<0.001)$ which was similar to the study represented by Wescott ${ }^{4}$, Marlow $^{5}$ and Bethard ${ }^{6}$. The lowest sagittal length of second cervical vertebrae in male was greater than that of female. However upper limits in both sexes were closely related.

Wescott ${ }^{4}$ examined 400 second cervical vertebrae from Hamann-Todd and Terry anatomical collection. Among them 100 was Black and 100 was White people of each sex. The race of the Black is Negroid and the White is Caucasoid ${ }^{8}$. In Black, he reported that the mean sagittal length was $51.06 \pm 2.85 \mathrm{~mm}$ in male and $47.14 \pm 2.39 \mathrm{~mm}$ in female. In White, the mean sagittal length was $52.36 \pm 2.42 \mathrm{~mm}$ in male and $47.68 \pm 2.41 \mathrm{~mm}$ in female. Allbright ${ }^{7}$ taken vertebrae from 119 individuals of an immigrant population of European ancestry collected from the University of Tennessee William M. Bass Skeletal Collection. According to the study of Allbright mean sagittal length of second cervical vertebrae was 50.15 $\pm 2.12 \mathrm{~mm}$ in male and $47.54 \pm 2.54 \mathrm{~mm}$ in female. Marlow and pastor ${ }^{5}$ studied 153 second cervical vertebrae of European ancestry collected from Natural History Museum, London. The race of the European ancestry is Caucasoid ${ }^{9}$. They found 50.22 $\pm 2.45 \mathrm{~mm}$ and $46.50 \pm 2.72 \mathrm{~mm}$ the mean sagittal length in male and female respectively.

In the present study the mean value in both sexes was lower than that of other researchers. The reason for this might be due to racial and geographical variation. The present study was carried out in second cervical vertebrae collected from Bangladesh. Skeletons that are available in Bangladesh also come from neighboring countries. Bangladeshis are mixed race of Negroid, Caucasoid and Mongoloid ${ }^{10}$. However the highest sagittal length in present study was nearly similar to the mean values of others researchers.

Measurement directly taken from autopsy cases is more accurate and reliable than that of dry ossified samples. We cannot claim that these second cervical vertebrae belong to Bangladeshi people. So in further studies along with larger sample size we require second cervical vertebrae from Bangladeshi cadaver to get more precise picture of Bangladeshi people which will help to establish a baseline data from which we can compare different morphometric parameters of second cervical vertebrae with the findings of other researches.

\section{Conclusion}

The study revealed that the male second cervical vertebra was larger than the female second cervical vertebra. Further radiographic study of living second cervical vertebrae and comparison of the radiographic findings of human dry ossified second cervical vertebrae might be beneficial in this regard.

\section{References}

1. Sinnatamby CS. Last's Anatomy Regional and Applied. $11^{\text {th }}$ ed. London : Churchill Livingstone 2006. 
2. Newell RLM, Back. In: S. Standring, 2008. Gray's Anatomy: The Anatomical Basis of Clinical Practice. $40^{\text {th }}$ ed. London: Churchill Livingstone 2008: 705-74.

3. Duray SM, Morter HB, Smith FJ. Morphological Variation in Cervical Spinous Processes: Potential Applications in the Forensic Identification of Race from the Skeleton. Journal of Forensic Sciences, 1999; 44(5): 937-44.

4. Wescott DJ. Sex variation in the second cervical vertebra. Journal of Forensic Sciences, 2000; 45(2): 462-66.

5. Marlow EJ, Pastor RF. Sex Determination Using the Second Cervical Vertebra - A Test of the Method. Journal of Forensic Sciences 2011; 56(1): 165-69.
6. Bethard JD, Seet BL. Sex determination from the second cervical vertebra: A test of Wescott's method on a modern American sample. Journal of Forensic Sciences 2012: 1-3.

7. AllbrightAS. Sexual dimorphism in the vertebral column. Master of Arts Degree. The University of Tennessee, Knoxville. 2007.

8. Shukla IC.. List of Human Races. [online]. Available at: www.buzzle.com/articles/list-ofhuman-races.html 2012. [Accessed 25 March 2013].

9. Metapedia, European race. [online] Available at: en. metapedia. Org/wiki/European_race. 16 March 2013. [Accessed 26 March 2013].

10. Wikipedia, Bangladeshi People. [online] Available at: en. Wikipedia. Org/wiki/ Bangladeshi_peoples. 17 February 2013. [Accessed 26 March 2013]. 